\title{
Pathogenesis, diagnosis and management of hyperkalemia
}

\author{
Anja Lehnhardt • Markus J. Kemper
}

Received: 8 July 2010 /Revised: 1 October 2010 /Accepted: 4 October 2010 / Published online: 22 December 2010

(C) IPNA 2010

\begin{abstract}
Hyperkalemia is a potentially life-threatening condition in which serum potassium exceeds $5.5 \mathrm{mmol} / \mathrm{l}$. It can be caused by reduced renal excretion, excessive intake or leakage of potassium from the intracellular space. In addition to acute and chronic renal failure, hypoaldosteronism, and massive tissue breakdown as in rhabdomyolysis, are typical conditions leading to hyperkalemia. Symptoms are non-specific and predominantly related to muscular or cardiac dysfunction. Treatment has to be initiated immediately using different therapeutic strategies to increase potassium shift into the intracellular space or to increase elimination, together with reduction of intake. Knowledge of the physiological mechanisms of potassium handling is essential in understanding the causes of hyperkalemia as well as its treatment. This article reviews the pathomechanisms leading to hyperkalemic states, its symptoms, and different treatment options.
\end{abstract}

Keywords Hyperkalemia · Potassium · Renal failure ·

Salbutamol

\section{Introduction}

Potassium is the most abundant intracellular cation (100$150 \mathrm{mmol} / \mathrm{l}$ ) and is critical in many physiological functions. Absorption of potassium from the gastrointestinal tract is rapid and usually complete. Depending on diet, the normal daily intake can vary. Common potassium-rich foods

A. Lehnhardt $\cdot$ M. J. Kemper $(\bowtie)$

Department of Pediatric Nephrology,

University Medical Center Hamburg-Eppendorf,

Martinistr. 5,

20246, Hamburg, Germany

e-mail: kemper@uke.de include fruits, potatoes, beans, and grains; in contrast, high-fat diets usually contain low amounts of potassium (Table 1). Low extracellular potassium concentrations of $3.5-5.5 \mathrm{mmol} / 1$ are maintained by distinct renal and extrarenal mechanisms. The major key effector is the energy-consuming enzyme $\mathrm{Na}^{+} / \mathrm{K}^{+}$-ATPase, located in the plasma membrane of cells, which pumps $\mathrm{Na}^{+}$out of and $\mathrm{K}^{+}$ into the cell in a $3: 2$ ratio $\left(3 \mathrm{Na}^{+}: 2 \mathrm{~K}^{+}\right)$. The $\mathrm{Na}^{+} / \mathrm{K}^{+}$-ATPase helps to maintain the resting potential and avail transport, and helps to regulate cellular volume as well as intracellular calcium content. Extrarenal mechanisms are able to shift $\mathrm{K}^{+}$ from extra- to intracellularly, but the excretion of potassium mainly occurs in the kidneys. Renal adaptive mechanisms allow the kidneys to maintain potassium homeostasis until the glomerular filtration rate (GFR) drops to less than $15 \mathrm{ml} / \mathrm{min} / 1.73 \mathrm{~m}^{2}$. Approximately $10 \%$ of the daily potassium intake is cleared via the gastrointestinal tract. In the presence of renal failure, the proportion of potassium excreted through the gut can increase, but is subject to high inter-individual variability [1].

\section{Renal mechanisms of potassium handling}

Handling of potassium in the nephron depends on passive and active mechanisms. Potassium is filtered in the glomerulus and almost completely reabsorbed in the proximal tubule and the loop of Henle. Excretion mainly occurs in the cortical collecting duct [2]. It should be noted, however, that reabsorption and secretion of potassium occur simultaneously, and that many modulators are important, such as diet, adrenal steroids, and acid-base balance.

Approximately $60-75 \%$ of the filtered potassium is reabsorbed in the proximal tubule (PT) by diffusion and solvent drag, mainly coupled to $\mathrm{Na}^{+}$transport. The 
Table 1 Potassium content of selected foods

\begin{tabular}{ll}
\hline Foods and drinks & Potassium content $(\mathrm{mmol})$ \\
\hline 1 small banana $(85 \mathrm{~g})$ & 8.6 \\
Blueberries $(100 \mathrm{~g})$ & 1.9 \\
White mushrooms $(75 \mathrm{~g})$ & 8.1 \\
Broccoli, cooked $(75 \mathrm{~g})$ & 5.8 \\
Green beans, cooked $(75 \mathrm{~g})$ & 3.9 \\
Onions, cooked $(75 \mathrm{~g})$ & 1.5 \\
& \\
French fries $(150 \mathrm{~g})$ & 17.7 \\
Parboiled rice $(150 \mathrm{~g})$ & 2.2 \\
Spaghetti, without egg $(150 \mathrm{~g})$ & 2.3 \\
Orange juice $(200 \mathrm{ml})$ & \\
Milk, full fat $(200 \mathrm{ml})$ & 7.9 \\
Coca Cola $(200 \mathrm{ml})$ & 7.7 \\
& 0.1 \\
Potato crisps $(20 \mathrm{~g})$ & 1.8 \\
Milk chocolate bar $(20 \mathrm{~g})$ & 5.1 \\
White chocolate $(20 \mathrm{~g})$ & 2.4 \\
Wine gums $(20 \mathrm{~g})$ & \\
\hline
\end{tabular}

mechanisms involved are not yet completely understood. The $\mathrm{Na}^{+} / \mathrm{H}^{+}$antiporter is the most important system in this respect, and paracellular shunt-pathways are also present. Diffusion is driven by lumen-negative electrical potential created by the $\mathrm{Na}^{+} / \mathrm{K}^{+}$-ATPase in the second half of the proximal tubule, which creates high $\mathrm{Cl}^{-}$concentrations in the lumen.

Approximately $15-20 \%$ of the filtered potassium is reabsorbed in the thick ascending limb of the Loop of Henle (TAL). Several co-transporters and ion channels are involved in the complex regulatory system of potassium reabsorption. The best characterized is the $\mathrm{Na}-\mathrm{K}-2 \mathrm{Cl}$ cotransporter (NKCC2), which transports potassium out of the tubular fluid and is inhibited by loop diuretics (furosemide). Some of the potassium recycles back into the tubular fluid via $\mathrm{K}$ channel ROMK (renal outer medullary $\mathrm{K}^{+}$channel) in the apical membrane, but a fraction of it moves into the interstitial fluid. The TAL establishes the potential for countercurrent trapping of potassium in the medulla in a manner similar to that for $\mathrm{Na}^{+}$and $\mathrm{NH}_{4}^{+}$. Basolateral transporters include a $\mathrm{KCl}$ cotransporter.

The distal convoluted tubule (DCT) is the site of the apical sodium chloride cotransporter (NCCT), which is blocked by thiazides [3]. It modulates excretion of not only potassium but also calcium and magnesium. NCCT and ROMK channels seem to regulate potassium excretion under the influence of serine/threonine kinases, especially lysine-deficient protein kinase- 1 and 4 (WNK-1 and WNK4) [4]. There is evidence that the calcium-sensing receptor (CaSR) influences the renal ion transport, amongst others by inhibiting the activity of ROMK [5].

At least two circulating factors are required for the regulation of renal $\mathrm{K}^{+}$secretion by the cortical collecting duct (CCD), the main site of renal potassium excretion, aldosterone, and a second as yet unidentified factor that increases the number of conducting $\mathrm{K}^{+}$channels [6].

Aldosterone as key regulator of renal potassium homeostasis binds to the nuclear mineralocorticoid receptor (MR) within the distal tubule and the principal cells in the CCD. It activates the basolateral $\mathrm{Na}^{+} / \mathrm{K}^{+}$-ATPase, thereby increasing $\mathrm{Na}^{+}$and water reabsorption into the blood and secretion of $\mathrm{K}^{+}$into the urine. Aldosterone also upregulates the amiloride sensitive sodium channels $(\mathrm{ENaCs})$ in the apical membrane of $\mathrm{CCD}$ and stimulates $\mathrm{H}^{+}$secretion by intercalated CCD cells, thereby influencing acid/base balance [7].

$\mathrm{K}^{+}$secretion can be partially counteracted by reabsorption by the intercalated cells in the cortical and outer medullary collecting tubules [8, 9]. Vasopressin increases $\mathrm{K}^{+}$excretion in the medullary collecting duct while promoting antidiuresis [10].

\section{Extrarenal regulatory mechanisms of potassium metabolism}

Acid-base balance can affect the balance between cellular and extracellular potassium concentration. Acidosis increases the plasma $\mathrm{K}^{+}$concentration by inducing a net shift of $\mathrm{K}^{+}$from the cellular to the extracellular compartment in exchange with $\mathrm{H}^{+}$, also leading to a reduced tubular secretion of potassium.

Insulin is important in preventing a large change in extracellular fluid (ECF) $\mathrm{K}^{+}$concentration as it increases potassium uptake into liver and muscle cells by stimulating $\mathrm{Na}^{+} / \mathrm{K}^{+}$-ATPase. Large increases in ECF $\mathrm{K}^{+}$concentration (>1-1.5 mmol/l) stimulate insulin secretion, which promotes shift of excess $\mathrm{K}^{+}$into the intracellular compartment.

Lastly, catecholamines (adrenaline, noradrenaline, dopamine) binding to beta- 2 receptors on muscle cells stimulate the $\mathrm{Na}^{+} / \mathrm{K}^{+}$-ATPase and cause increased $\mathrm{K}^{+}$shift into cells.

\section{Pathogenesis of hyperkalemia}

Hyperkalemia may result from an increase in total body potassium secondary to imbalance of intake vs. excretion or from maldistribution between intra- and extracellular space. 


\section{Excessive intake}

In patients with unimpaired renal function and intact other regulatory mechanisms, large amounts of potassium are needed to achieve hyperkalemia [11]. Whereas in patients with impaired renal function, especially when GFR is $<15 \mathrm{ml} / \mathrm{min}$, a slight increase in potassium intake can cause severe hyperkalemia.

\section{Impaired elimination of potassium}

1) Renal insufficiency acute or chronic: reduced GFR (especially $<15 \mathrm{ml} / \mathrm{min} / 1.73 \mathrm{~m}^{2}$ ) with low urine flow (and therefore low sodium delivery to the distal tubule) lead to decreased renal excretion of potassium.

2) Medications interfering with urinary potassium excretion (also see Table 2): of special clinical relevance are potassium-sparing diuretics (amiloride or spironolactone), cyclosporine, trimetoprim [12]. Non-steroidal anti-inflammatory drugs (NSAIDs; ibuprofen, naproxen) and ACEI (angiotensin converting enzyme inhibitors) as well as angiotensin receptor inhibitors can cause a decrease in aldosterone and GFR and thereby lead to hyperkalemia [13]. Combined treatment with spironolactone and ACE inhibitors, especially in patients with renal impairment or heart failure, has to be monitored very carefully.
3) Hypoaldosteronism may either be primary (e.g. M. Addison) or secondary (e.g. chronic renal failure), resulting in hyperkalemia accompanied by urinary salt wasting, leading to volume depletion and hypotension $[14,15]$. A similar picture can be seen in patients with obstructive uropathy and renal tubular acidosis [16, 17].

4) Pseudohypoaldosteronism (PHA) refers to a heterogeneous group of disorders of electrolyte metabolism characterized by hyperkalemia, metabolic acidosis, and normal GRF [18]. PHA type I caused by autosomal dominant mutations in the human mineralocorticoid receptor $(M R)$ gene is limited to the kidneys. PHA type I secondary to loss of function mutations of the $\mathrm{ENaC}$ not only affects the kidney but also the lungs, colon, and sweat and salivary glands. PHA-II (also known as Gordon's syndrome) is a rare familial renal tubular defect caused by loss of function mutations in WNK1 or WNK4 [19]. Gordon's syndrome is characterized by volume expansion, suppressed renin, and reduced mineralocorticoid-induced renal clearance of potassium leading to hypertension and hyperkalemia, and hyperchloremic acidosis with normal glomerular filtration rate [20].

5) Congenital adrenal hyperplasia (CAH): caused by mutation or deletion of any of the genes that code for enzymes involved in cortisol or aldosterone synthesis

Table 2 Drugs inducing hyperkalemia

\begin{tabular}{|c|c|}
\hline Drug & Mechanisms \\
\hline Amiloride & Blocking sodium channels of luminal membrane of principal cells \\
\hline \multirow[t]{2}{*}{ Spironolactone } & Mineralocorticoid receptor antagonist (competing with aldosterone) \\
\hline & Inhibition of adrenal aldosterone biosynthesis \\
\hline \multirow[t]{3}{*}{ Cyclosporine, Tacrolimus } & Inhibition of adrenal aldosterone biosynthesis \\
\hline & Induction of chloride channel shunt \\
\hline & Increasing potassium efflux from cells \\
\hline Trimetoprim, Pentamidine & Blocking of sodium channels in the luminal membrane of principal cells \\
\hline NSAIDs & Induction of hyporeninemic hypoaldosteronism through inhibiting renal prostaglandin synthesis \\
\hline \multirow{2}{*}{$\begin{array}{l}\text { ACE inhibitors, Angiotensin-II } \\
\text { receptor antagonists }\end{array}$} & Reduction in adrenal aldosterone biosynthesis through interrupting renin-aldosterone axis \\
\hline & Reduction in effective glomerular filtration rate \\
\hline \multirow[t]{2}{*}{ Beta blockers } & Inhibiting renin secretion \\
\hline & Decrease in cellular potassium uptake \\
\hline \multirow{2}{*}{$\begin{array}{l}\text { Calcium channels blockers } \\
\text { (Nifedipine, Amlodipine) }\end{array}$} & Inhibition of adrenal aldosterone biosynthesis \\
\hline & Reduction in aldosterone secretion \\
\hline Succinylcholine & Leakage of potassium out of cells through depolarization of cell membranes \\
\hline Digoxin & Inhibition of $\mathrm{Na}^{+} / \mathrm{K}^{+}$-ATPase \\
\hline \multirow[t]{2}{*}{ Heparin } & Inhibition of adrenal aldosterone biosynthesis \\
\hline & Decreasing number and affinity of angiotensin-II receptors \\
\hline Mannitol & $\begin{array}{l}\text { "Solvent drag phenomena" whereby potassium shifts out of cells due to the body's attempt to maintain } \\
\text { isotonicity while undergoing a hypertonic infusion }\end{array}$ \\
\hline
\end{tabular}

NSAIDs non-steroidal anti-inflammatory drugs 
results. Approximately $90 \%$ of cases of $\mathrm{CAH}$ are due to 21-hydroxylase deficiency [21]. The particular phenotype and degree of hyperkalemia depends on the sex of the individual, the location of the block in synthesis, and the severity of the genetic deletion or mutation.

6) Congestive heart failure: reduced renal function and treatment with drugs interfering with renal potassium excretion often lead to hyperkalemia [14, 22].

7) Constipation: enteral elimination of potassium can be decreased and therefore lead to hyperkalemia, which again might lead to reduced bowel movements. Patients with bowel emptying problems secondary to myelodysplasia or VACTERL-association are at special risk.

\section{Increased shift of potassium from intra to extracellular space}

1) Acidosis: Mineral acidosis is more likely to cause a shift of potassium from intracellular space into extracellular space than organic acidosis.

2) Diabetes mellitus: reduced insulin levels lead to accumulation of potassium in the extracellular space [23].

3) Acute increase in osmolality secondary to hyperglycemia or mannitol infusion causes potassium to exit from cells [24].

4) Acute cell-tissue breakdown: if extensive cell damage occurs, intracellular potassium is released into extracellular space. This can be the case in patients with rhabdomyolysis, tumorlyis, hemolysis, or after massive transfusion.

5) Drugs (also see Table 2): digoxin and beta-blockers (especially non-selective ones) inhibit the basolateral $\mathrm{Na}^{+} / \mathrm{K}^{+}$-ATPase [25]. Succinylcholine, especially when given to patients with burn injuries, immobilization, or inflammation [26].

6) Hyperkalemic periodic paralysis: rare condition with mutations of the muscular sodium channel, resulting in paralytic episodes associated with elevated $\mathrm{K}^{+}$levels [27].

\section{Diagnosis of hyperkalemia}

Hyperkalemia can be classified according to serum potassium into mild (5.5-6.5 mmol/1), moderate $(6.5-7.5 \mathrm{mmol} /$ 1) and severe ( $>7.5 \mathrm{mmol} / \mathrm{l})$ hyperkalemia.

Hyperkalemia is rarely associated with symptoms, occasionally patients complain of palpitations, nausea, muscle pain, or paresthesia. However, moderate and especially severe hyperkalemia can lead to disturbances of cardiac rhythm, which can be fatal [28, 29]. Electrocardiography (ECG) monitoring is mandatory in patients with serum potassium $>6.5 \mathrm{mmol} / \mathrm{l}$. ECG changes may present as non-specific repolarization abnormalities, "peaked" T-waves, and QRS widening as well as depression of ST-segment.

Examination and investigations should be systematic and always include assessment of cardiac function, kidneys, and urinary tract as well as hydration status and neurological evaluation. Laboratory workup should be comprehensive, especially if the underlying cause is unknown (Table 3). Figure 1 gives a diagnostic algorithm based on GFR and aldosterone levels.

\section{Pseudohyperkalemia}

If elevated serum potassium is found in an asymptomatic patient with no apparent cause, factitious hyperkalemia should be considered. This results from leakage of potassium from the intracellular space during or after blood sampling. In these cases, elevation of serum potassium concentration does not reflect the level of serum potassium in vivo and no treatment is needed. Especially in pediatrics, mechanical hemolysis can occur during difficult blood draws, and even more in samples with lymphocytosis or thrombocytosis. Especially when capillary samples are taken, excess alcohol on the skin should be avoided, as it is the primary cause of the hemolysis in this process. Correction factors have been discussed, but blood usually has to be drawn again [30].

\section{Management of hyperkalemia}

Therapeutic strategies should be individualized, taking into account the degree and the cause of hyperkalemia. Management should not only rely on ECG changes but be guided by the clinical scenario and serial potassium measurements [29, 31]. Treatment has to be more aggressive the higher and the faster the rise of the potassium level, and the greater the evidence of toxicity (ECG changes). Most medical therapies for hyperkalemia provide only transitory improvement by shifting $\mathrm{K}^{+}$into intracellular space without actually eliminating potassium. These therapeutic measures often are sufficient in acute hyperkalemia in patients without significant renal impairment, where an increase in renal potassium excretion can be achieved. In patients with moderate to severe hyperkalemia $(>6.5 \mathrm{mmol} / \mathrm{l})$, especially those with renal impairment, all therapeutic strategies including renal replacement therapy may be necessary [32]. 
Table 3 Laboratory investigations in hyperkalemia

Differential diagnosis

Blood test

Full blood count

Blood gas analysis

Serum osmolality

Creatinine, urea

CK

ALT

LDH

Glucose, glycosylated hemoglobin

Renin, angiotensin, aldosterone

Cortisol, 11-beta hydroxylase or 21-hydroxylase or

$17-\mathrm{OH}$ progesterone in plasma

Urine test

Potassium, sodium, creatinine

Albumin

TTKG

(S Osm * U Potassium) / (S Potassium * U Osm)

Index of potassium secretory activity in the distal tubule

Only valid when urine osmolality $>300$ and urine sodium $>25 \mathrm{mmol} / \mathrm{l}$
Hemolytic anemia

HUS

Thrombocytosis

Infection \& sepsis

Acidosis

Calculation of TTKG

Acute and chronic renal insufficiency

Rhabdomyolysis

Hemolysis, tumor lysis

Hemolysis, tumor lysis

Diabetes mellitus

Hyporeninemic hypoaldosteronism, pseudohypoaldosteronism

Reduced enzyme activities in congenital adrenal hyperplasia

Salt wasting

Proteinuria

TTKG expected to be high (usually $>10$ ) in hyperkalemia when renal response is intact. An inappropriately low TTKG in a hyperkalemic patient suggests hypoaldosteronism or a renal tubule defect [39]

Test is most useful in distinguishing patients who have mineralocorticoid deficiency versus resistance by observing a change in TTKG values after administration of mineralocorticoid: increase in TTKG in mineralocorticoid-deficient but not aldosterone resistant states

TTKG Transtubular potassium gradient, $C K$ creatinine kinase, $A L T$ alanine transaminase, $L D H$ lactate dehydrogenase

The following steps often have to be addressed simultaneously. Additionally, if unknown, the cause of hyperkalemia has to be determined to prevent future episodes. Dosage and side-effects of drugs are given in Table 4.

Step 1: Evaluate patient for potential toxicities and initiate ECG monitoring

- If patient has severe hyperkalemia or shows ECG changes, transfer to intensive care unit (ICU) immediately.

- Ca-Gluconate $10 \%$ can be used in patients with cardiac symptoms to stabilize membrane potential and positively influence bradycardia and ECG changes. Contraindications: digoxin-intoxication, hypercalcemic states.

Step 2: Identify and immediately eliminate sources of potassium intake

- Review prescriptions and stop oral or parenteral potassium supplements.

- Stop all drugs that might cause or aggravate hyperkalemia.
- Input of dieticians might be needed to identify potassium-rich foods (check for "special diets"), especially in patients with chronic renal failure.

Step 3: Increase potassium shift from extra- to intracellular space

- Dextrose and/or insulin infusion. An effect can often be seen immediately but response remains unpredictable. Close electrolyte and blood glucose monitoring is needed, hypoglycemia being the main side-effect. Aim to maintain blood glucose 10$15 \mathrm{mmol} / \mathrm{l}$.

- Beta-adrenergic agonists (salbutamol, reproterol) stimulate potassium to shift from extra to intracellular space via $\mathrm{Na}^{+} / \mathrm{K}^{+}$-ATPase as described above. Salbutamol can be applied via nebulizer or given intravenously. If given iv, the lowering effect of salbutamol is quite predictable with a mean decrease of 1.6$1.7 \mathrm{mmol} / 1$ after $2 \mathrm{~h}$ [33]. It can cause tachycardia. Salbutamol has been shown to be safe and even superior to rectal cation-exchange resin in nonoliguric preterms with hyperkalemia [34]. 


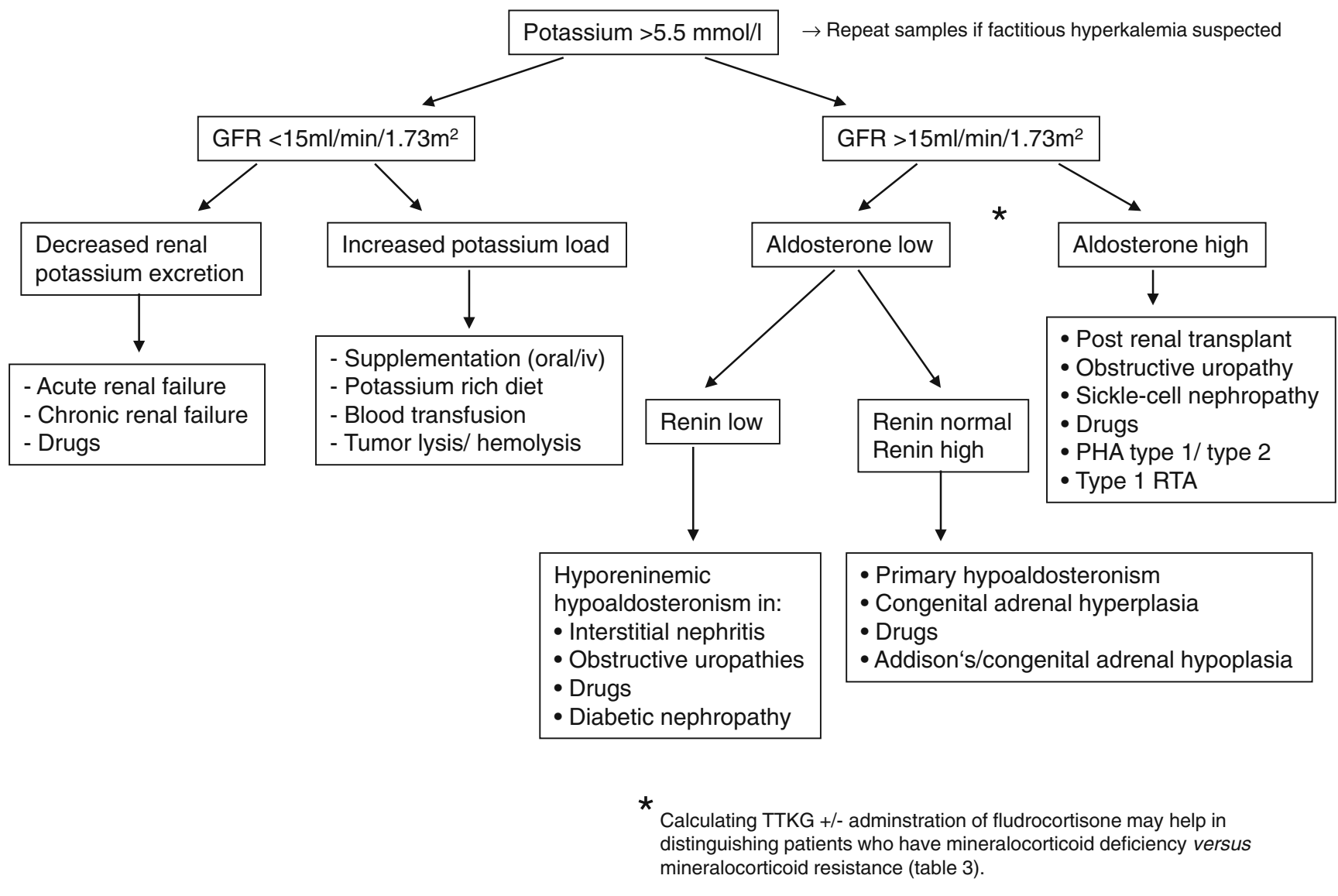

Fig. 1 Diagnostic algorithm in hyperkalemia; adapted from Clinical Paediatric Nephrology. Used with permission from [40] RTA renal tubular acidosis

Table 4 Drugs used for treatment of hyperkalemia

\begin{tabular}{|c|c|c|c|}
\hline Drug & Dose & $\begin{array}{l}\text { Rapidity of } \\
\text { action }\end{array}$ & Side-effects/complications \\
\hline Dextrose/insulin & $\begin{array}{l}2.5-5 \mathrm{ml} / \mathrm{kg} / \mathrm{h} 20 \% \text { dextrose }(0.5-1 \mathrm{~g} / \mathrm{kg} / \mathrm{h}) \\
\text { with insulin } 0.2 \text { units for every gram of } \\
\text { glucose administered }\end{array}$ & Fast & $\begin{array}{l}\text { Hypoglycemia, hyperosmolarity, volume } \\
\text { overload }\end{array}$ \\
\hline $\begin{array}{l}\text { Salbutamol (ten drops of standard } \\
\text { sabutamol inhalation solution } \\
\text { contain } 2.5 \mathrm{mg} \text { ) }\end{array}$ & $\begin{array}{l}\text { iv: } 4-5 \mu \mathrm{g} / \mathrm{kg} \text { in } 15 \mathrm{ml} \text { of } 5 \% \text { dextrose/ } \\
\text { water, short infusion over } 15 \mathrm{~min} \\
\text { Nebulized: } 2.5 \mathrm{mg} \text { if }<25 \mathrm{~kg} \text { and } 5 \mathrm{mg} \text { if } \\
>25 \mathrm{~kg}\end{array}$ & Fast & Tachycardia \\
\hline Sodium bicarbonate $8.4 \%$ & $\begin{array}{l}1-2 \mathrm{mmol} / \mathrm{kg} \text { over } 30-60 \mathrm{~min} \text { or calculated } \\
\text { on base-deficit }\end{array}$ & Intermediate & Sodium load (hypertension) \\
\hline Furosemide & $1-2 \mathrm{mg} / \mathrm{kg}$ & Intermediate & Ototoxicity, nephrotoxicity \\
\hline Ion exchange resins & $\begin{array}{l}\text { Given p.o. or p.r. calcium resonium } 1 \mathrm{~g} / \mathrm{kg} \\
\text { sodium resonium } 1 \mathrm{~g} / \mathrm{kg}\end{array}$ & Slow & $\begin{array}{l}\text { p.o.: nausea, constipation or even paralytic } \\
\text { ileus. Diarrhea if preparations come } \\
\text { premixed with sorbitol } \\
\text { p.r.: cecal perforation }\end{array}$ \\
\hline Ca-Gluconate $10 \%$ & $\begin{array}{l}0.5-1 \mathrm{ml} / \mathrm{kg} \text { over } 5-10 \mathrm{~min} \text {, preferably ad- } \\
\text { ministered via central venous access }\end{array}$ & & $\begin{array}{l}\text { Hypercalcemia, tissue necrosis } \\
\text { NOTE: Ca-Gluconate does not have a } \\
\text { potassium-lowering effect }\end{array}$ \\
\hline
\end{tabular}


- Sodium bicarbonate, preferably given to patients who are acidotic. In hemodialysis patients with hyperkalemia it has only a moderate effect if given as prolonged infusion [35]. NOTE: a rise in $\mathrm{pH}$ can aggravate hypocalcemia.

Step 4: Increase potassium excretion

- Loop diuretics (furosemide) inhibit the inward transport of potassium via $\mathrm{NKCC} 2$ channel in the TAL. Even in chronic hemodialysis patients, treatment with loop diuretics may be of value if the patient has some residual renal function [36].

- Ion-exchange resins (containing calcium or sodium) aim to keep enteral potassium from being resorbed. More effective if given orally. Enemas should be retained at least 30-60 min. [37]. Onset within 1-2 $\mathrm{h}$, lasting 4-6 h.

- Renal replacement therapy (RRT) is the ultimate measure in severe hyperkalemia. Hemodialysis (HD) provides a substantially higher potassium clearance (removal of $50-80 \mathrm{mmol}$ of $\mathrm{K}^{+}$in a 4$\mathrm{h}$ session) than continuous forms of RRT. Continuous veno-venous hemofiltration $(\mathrm{CVVH})$ can more satisfactorily provide long-term control of potassium. Choice of method depends on local circumstances and hemodynamics of the patients, as critical ill patients will rarely tolerate HD sessions [38].

In summary and conclusion, the effective and rapid diagnosis and management of acute and chronic hyperkalemia in children, especially if renal function is impaired, is clinically relevant and can be life-saving. In treatment of moderate to severe hyperkalemia, the combination of medications with different therapeutic approaches is usually effective, and often methods of blood purification can be avoided. In children with severe hyperkalemia and major ECG abnormalities, conservative efforts should be initiated immediately to stabilize the patient, but management should include rapid facilitation of renal replacement treatment.

\section{Multiple-choice questions}

(Answers appear following the reference list)

1) Which is the most important site of $\mathrm{K}^{+}$secretion in the kidney?
a) proximal tubule
b) thin descending limb of loop of Henle
c) thick ascending limb of loop of Henle
d) distal tubule convolute
e) cortical collecting duct

2) Which drug does not cause hyperkalemia?
a) furosemide
b) amiloride
c) digoxin
d) labetalol
e) trimetoprim

3) Which of the following clinical conditions typically causes hyperkalemia (answer true or false for (a) through (e))
a) acute renal failure
b) acute myocardial infarction
c) rhabdomyolysis
d) hyperaldosteronism
e) Gordon's syndrome

4) In managing a patient with severe hyperkalemia: (answer true or false for (a) through (e))
a) first aspect of management is to establish the underlying diagnosis
b) ECG may show QRS widening
c) the patient is invariably vomiting
d) in the short term, calcium gluconate may reduce risk of arrhythmias
e) ventricular fibrillation and death may occur

5) The mode of action of salbutamol and glucose/insulin is mediated by
a) an increase of renal elimination of potassium
b) a reduction of intestinal potassium intake
c) stabilization of membrane potential
d) an increase of potassium shift from extracellular into intracellular compartment
e) hypoglycemia

6) In anuric patients, treatment of hyperkalemia
a) should include diuretics
b) by increasing elimination of potassium via the gut (e.g., by enemas) may be an important option
c) is an infrequent problem
d) is always associated with cardiac symptoms
e) by shifting potassium into the intracellular depart- ment is ineffective

\section{References}

1. Klevay LM, Bogden JD, Aladjem M, Sandstead HH, Kemp FW, Li W, Skurnick J, Aviv A (2007) Renal and gastrointestinal potassium excretion in humans: new insight based on new data and review and analysis of published studies. J Am Coll Nutr 26:103-110

2. Kemper MJ (2009) Potassium and magnesium physiology. In: Ronco C, Bellomo R, Kellum JA (eds) Critical Care Nephrology, pp $478-482$ 
3. Smith SM (2010) Thiazide diuretics. N Engl J Med 362:659-660, author reply 660

4. Liu Z, Wang HR, Huang CL (2009) Regulation of ROMK channel and $\mathrm{K}+$ homeostasis by kidney-specific WNK1 kinase. J Biol Chem 284:12198-12206

5. Huang C, Miller RT (2007) Regulation of renal ion transport by the calcium-sensing receptor: an update. Curr Opin Nephrol Hypertens 16:437-443

6. Biner HL, Arpin-Bott MP, Loffing J, Wang X, Knepper M, Hebert SC, Kaissling B (2002) Human cortical distal nephron: distribution of electrolyte and water transport pathways. J Am Soc Nephrol 13:836-847

7. Palmer LG, Frindt G (2000) Aldosterone and potassium secretion by the cortical collecting duct. Kidney Int 57:1324-1328

8. Stanton BA, Biemesderfer D, Wade JB, Giebisch G (1981) Structural and functional study of the rat distal nephron: effects of potassium adaptation and depletion. Kidney Int 19:36-48

9. Stetson DL, Wade JB, Giebisch G (1980) Morphologic alterations in the rat medullary collecting duct following potassium depletion. Kidney Int 17:45-56

10. Sonnenberg H, Honrath U, Wilson DR (1987) Effect of vasopressin analogue (dDAVP) on potassium transport in medullary collecting duct. Am J Physiol 252:F986-F991

11. Su M, Stork C, Ravuri S, Lavoie T, Anguish D, Nelson LS, Hoffman RS (2001) Sustained-release potassium chloride overdose. J Toxicol Clin Toxicol 39:641-648

12. Margassery S, Bastani B (2001) Life-threatening hyperkalemia and acidosis secondary to trimethoprim-sulfamethoxazole treatment. J Nephrol 14:410-414

13. Weir MR, Rolfe M (2010) Potassium homeostasis and ReninAngiotensin-aldosterone system inhibitors. Clin J Am Soc Nephrol 5:531-548

14. Sica DA, Gehr TW, Yancy C (2003) Hyperkalemia, congestive heart failure, and aldosterone receptor antagonism. Congest Heart Fail 9:224-229

15. Schambelan M, Sebastian A, Biglieri EG (1980) Prevalence, pathogenesis, and functional significance of aldosterone deficiency in hyperkalemic patients with chronic renal insufficiency. Kidney Int 17:89-101

16. Batlle DC, Arruda JA, Kurtzman NA (1981) Hyperkalemic distal renal tubular acidosis associated with obstructive uropathy. $\mathrm{N}$ Engl J Med 304:373-380

17. Karet FE (2009) Mechanisms in hyperkalemic renal tubular acidosis. J Am Soc Nephrol 20:251-254

18. Bogdanovic R, Stajic N, Putnik J, Paripovic A (2009) Transient type 1 pseudo-hypoaldosteronism: report on an eight-patient series and literature review. Pediatr Nephrol 24:2167-2175

19. Wilson FH, Disse-Nicodeme S, Choate KA, Ishikawa K, NelsonWilliams C, Desitter I, Gunel M, Milford DV, Lipkin GW, Achard JM, Feely MP, Dussol B, Berland Y, Unwin RJ, Mayan H, Simon DB, Farfel Z, Jeunemaitre X, Lifton RP (2001) Human hypertension caused by mutations in WNK kinases. Science 293:11071112

20. Klemm SA, Gordon RD, Tunny TJ, Thompson RE (1991) The syndrome of hypertension and hyperkalemia with normal GFR (Gordon's syndrome): is there increased proximal sodium reabsorption? Clin Invest Med 14:551-558

21. Speiser PW, White PC (2003) Congenital adrenal hyperplasia. N Engl J Med 349:776-788

22. Poggio R, Grancelli HO, Miriuka SG (2010) Understanding the risk of hyperkalaemia in heart failure: role of aldosterone antagonism. Postgrad Med J 86:136-142

23. Rodriguez-Soriano J, Vallo A, Ariceta G, Martul P, de la Rica I (1996) Renal tubular handling of potassium in children with insulin-dependent diabetes mellitus. Pediatr Nephrol 10:1-6
24. Conte G, Dal Canton A, Imperatore P, De Nicola L, Gigliotti G, Pisanti N, Memoli B, Fuiano G, Esposito C, Andreucci VE (1990) Acute increase in plasma osmolality as a cause of hyperkalemia in patients with renal failure. Kidney Int 38:301-307

25. Perazella MA (2000) Drug-induced hyperkalemia: old culprits and new offenders. Am J Med 109:307-314

26. Martyn JA, Richtsfeld M (2006) Succinylcholine-induced hyperkalemia in acquired pathologic states: etiologic factors and molecular mechanisms. Anesthesiology 104:158-169

27. Jurkat-Rott K, Holzherr B, Fauler M, Lehmann-Horn F (2010) Sodium channelopathies of skeletal muscle result from gain or loss of function. Pflugers Arch 460:239-248

28. Martinez-Vea A, Bardaji A, Garcia C, Oliver JA (1999) Severe hyperkalemia with minimal electrocardiographic manifestations: a report of seven cases. J Electrocardiol 32:45-49

29. Montague BT, Ouellette JR, Buller GK (2008) Retrospective review of the frequency of ECG changes in hyperkalemia. Clin J Am Soc Nephrol 3:324-330

30. Owens H, Siparsky G, Bajaj L, Hampers LC (2005) Correction of factitious hyperkalemia in hemolyzed specimens. Am J Emerg Med 23:872-875

31. Aslam S, Friedman EA, Ifudu O (2002) Electrocardiography is unreliable in detecting potentially lethal hyperkalaemia in haemodialysis patients. Nephrol Dial Transplant 17:1639-1642

32. Kemper MJ, Harps E, Muller-Wiefel DE (1996) Hyperkalemia: therapeutic options in acute and chronic renal failure. Clin Nephrol 46:67-69

33. Kemper MJ, Harps E, Hellwege HH, Muller-Wiefel DE (1996) Effective treatment of acute hyperkalaemia in childhood by shortterm infusion of salbutamol. Eur J Pediatr 155:495-497

34. Yaseen H, Khalaf M, Dana A, Yaseen N, Darwich M (2008) Salbutamol versus cation-exchange resin (kayexalate) for the treatment of nonoliguric hyperkalemia in preterm infants. Am J Perinatol 25:193-197

35. Blumberg A, Weidmann P, Ferrari P (1992) Effect of prolonged bicarbonate administration on plasma potassium in terminal renal failure. Kidney Int 41:369-374

36. Bragg-Gresham JL, Fissell RB, Mason NA, Bailie GR, Gillespie BW, Wizemann V, Cruz JM, Akiba T, Kurokawa K, Ramirez S, Young EW (2007) Diuretic use, residual renal function, and mortality among hemodialysis patients in the Dialysis Outcomes and Practice Pattern Study (DOPPS). Am J Kidney Dis 49:426-431

37. Bennett LN, Myers TF, Lambert GH (1996) Cecal perforation associated with sodium polystyrene sulfonate-sorbitol enemas in a 650-gram infant with hyperkalemia. Am J Perinatol 13:167-170

38. Ricci Z, Bellomo R, Ronco C (2009) Renal replacement techniques: descriptions, mechanisms, choices and controversies. In: Ronco C, Bellomo R, Kellum JA (eds) Critical Care Nephrology. Elsevier, Saunders, pp 1136-1141

39. Choi MJ, Ziyadeh FN (2008) The utility of the transtubular potassium gradient in the evaluation of hyperkalemia. J Am Soc Nephrol 19:424-426

40. Webb NJ, Postlethwaite RJ (2003) Clinical Paediatric Nephrology, 3rd edn. Oxford University Press, p 55

\section{Answers}

1. e

2. a

3. (a) true (b) false (c) true (d) false (e) true

4. (a) false (b) true (c) false (d) true (e) true

5. d

6. b 